\title{
Rancang Bangun Mesin Penjual Roti Otomatis Berbasis Internet of Things
}

\author{
Satria Hafizhuddin dan Hendra Kusuma \\ Departemen Teknik Elektro, Fakultas Teknologi Elektro, Institut Teknologi Sepuluh Nopember (ITS) \\ e-mail: hendraks@ee.its.ac.id
}

\begin{abstract}
Abstrak-Mesin penjual roti otomatis merupakan sebuah alat yang dirancang untuk mempermudah proses jual beli berbagai jenis roti, terutama bagi para penjual yang ingin meningkatkan jumlah penjualan namun terkendala oleh ruang yang terbatas. Mesin penjual roti otomatis ini sudah berbasis Internet of Thing, setiap komponen yang merupakan bagian dalam sistem ini terhubung satu sama lain dan mengirimkankan data terhadap server sehingga akan mempermudah dalam memonitor dan mengontrol mesin penjual otomatis pada lokasi yang jauh sekalipun, seperti mengetahui ketersediaan roti dan sudah berapa lama roti tersebut berada dalam mesin penjual roti otomatis ini. Untuk mengatur keluarnya roti digunakan motor DC sebagai aktuator untuk mendorong roti yang dihubungkan dengan kawat spiral. mesin penjual roti otomatis ini juga dilengkapi dengan pemanas guna mempertahankan suhu agar roti dapat tetap hangat. Arduino Uno dihubungkan dengan Raspberry Pi untuk menyimpan data sekaligus bertugas mengirimkan data dari setiap aktivitas yang terjadi terhadap server yang telah disiapkan. Alat yang dirancang mempunyai dimensi $30 \mathrm{~cm} \times 40 \mathrm{~cm} \times 60 \mathrm{~cm}$. Setelah dilakukan kalibrasi memiliki keberhasilan mengeluarkan roti sebesar 98,3\% dari 60 kali percobaan. Pengiriman data dari Arduino Uno menuju Raspberry Pi serta proses unggah pada server dan website dibutuhkan waktu \pm 3 detik dan untuk mendapatkan email pemberitahuan dibutuhkan waktu \pm 4 menit pada saat jaringan internet dan server dalam keadaan baik, terdapat dua skala yang bisa dipilih, yaitu $42^{\circ} \mathrm{C}$ dan $47^{\circ} \mathrm{C}$. dibutuhkan waktu 2 menit 30 detik untuk mencapai suhu $42^{\circ} \mathrm{C}$ dan 3 menit 30 detik untuk mencapai suhu $47^{\circ} \mathrm{C}$ dengan suhu awal $27^{\circ} \mathrm{C}$. Berdasarkan data pengujian error suhu pada sistem yang dibuat tidak pernah lebih dari $2^{\circ} \mathrm{C}$ dari suhu yang telah di tentukan.
\end{abstract}

Kata Kunci-Vending Machine, Internet of Things, Raspberry Pi, Kontrol Suhu

\section{PENDAHULUAN}

K EMAJUAN teknologi menuntut agar segala hal yang dilakukan manusia menjadi lebih baik dan termudahkan, termasuk dalam hal jual beli, agar transaksi dapat dilakukan kapanpun dan dimanapun tanpa mengurangi kualitas dari barang yang di jual.

Vending machine merupakan salah satu dari kemajuan teknologi yang berkembang sangat pesat di era modern ini, di Indonesia sudah begitu banyak vending machine yang dapat kita temukan, namun pada umumnya vending machine yang ada di Indonesia hanya menjual minuman sejenis softdrink dalam bentuk kaleng atau botol [1].

Berkaitan dengan dua hal diatas, penulis berusaha agar dapat terciptanya sebuah vending machine yang dapat menjual berbagai jenis roti dalam keadaan yang masih baik dan nyaman untuk di konsumsi di berbagai lokasi. Dalam hal ini, Internet of
Things berperan dalam mempermudah penjual di berbagai aspek, terutama untuk memonitor keadaan vending machine dan juga ketersediaan, serta kelayakan dari roti yang di jual sehingga dapat mempercepat proses penyediaan stok selanjutnya.

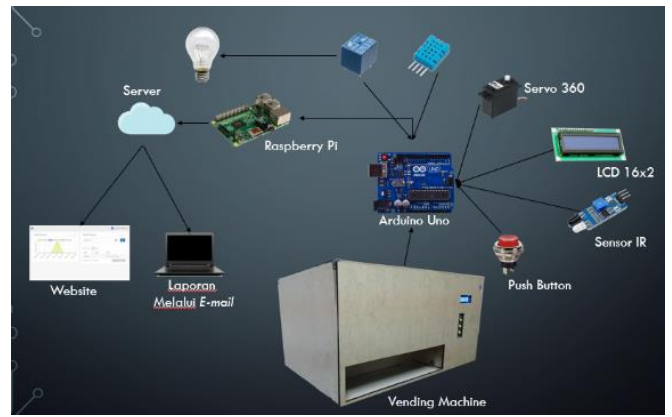

Gambar 1. Skema sistem mesin penjual roti otomatis dan komponen secara keseluruhan

\section{HARDWARE}

A. Sistem Mekanik

Sistem Mekanik pada Mesin Penjual Roti Otomatis berbasis Internet of Things ini menggunakan kayu MDF sebagai bahan utama pembuatannya, dengan ukuran $30 \mathrm{~cm} \times 40 \mathrm{~cm} \times 60 \mathrm{~cm}$, dirancang seperti vending machine pada umumnya, terdapat ruang rak, ruang pengambilan roti, dan ruang sistem.

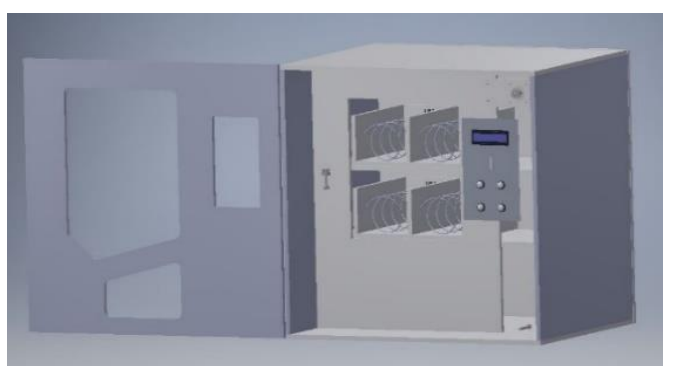

Gambar 2. Desain mekanik Vending Machine dengan aplikasi Inventor

\section{B. Sistem Elektrik}

Sistem Elektronik pada Mesin Penjual Roti Otomatis Berbasis Internet of Things ini menggunakan Arduino Uno sebagai kontrolel utama, lalu data yang didapatkan diberikan kepada Raspberry Pi untuk disimpan serta dikirimkan kepada server. Sistem Elektronik pada penelitian ini meliputi koneksi Arduino terhadap setiap komponen yang saling terhubung satu sama lain yaitu, sensor IR, motor servo, LCD, push button, DHT11,relay dan lampu pijar.

Berikut penjelasannya, 


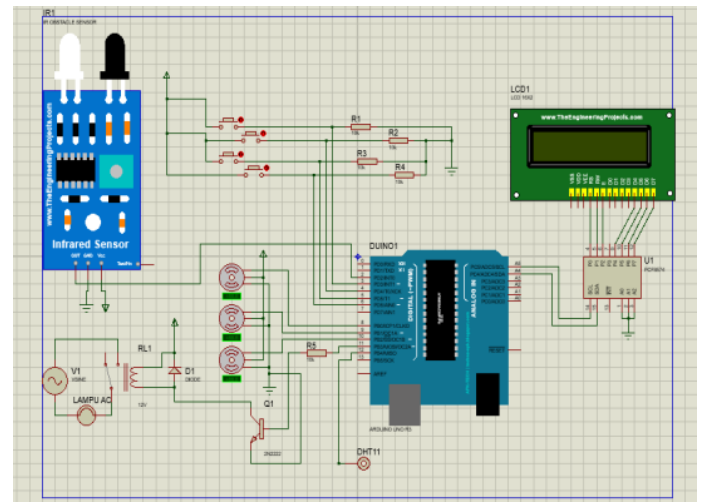

Gambar 3. Skema sistem elektrik, setiap komponen terhubung dengan Arduino Uno sebagai kontroler utama

\section{1) Power Supply}

Daya yang dibutuhkan sistem dihasilkan oleh adaptop $5 \mathrm{VDC} / 2 \mathrm{~A}$.

\section{2) Arduino Uno}

Arduino Uno berperan sebagai perangkat keras yang mengontrol komponen-komponen yang terdapat pada vending machine dan mengirimkan setiap aktifitas yang terjadi kepada Raspberry Pi.

\section{3) Sensor IR}

Sensor IR berguna untuk menggantikan fungsi dari pembayaran, memberikan masukan terhadap mikrokontroler agar dapat melanjutkan ke bagian sistem pengeluaran barang.[2]

\section{4) Sistem Pengeluaran Barang}

Sistem pengeluaran barang pada Vending machine ini memanfaatkan dari putaran servo continuous yang disambungkan dengan kawat spiral yang akan diputarkan sebanyak $360^{\circ}$ untuk sekali pengeluaran barang.

\section{5) Interface}

Interface akan memberikan masukan perintah ke mikrokontroler menggunakan push button. Selain itu, interface juga menerima keluaran yang ditunjukkan melalui LCD.

\section{6) DHT11}

DHT11 digunakan sebagai sensor untuk mendeteksi suhu pada vending machine agar dapat lebih mudah dalam menetapkan dan mengontrol suhuh pada bagian dalam vending machine. [3]

\section{7) Lampu Pijar}

Lampu pijar digunakan sebagai sumber panas pada bagian dalam vending machine agar dapat mempertahankan suhu sesuai yang diinginkan.

\section{8) Relay}

Relay berfungsi sebagai switch nyala dan tidak lampu pijar.

\section{9) Raspberry Pi}

Raspberry Pi berfungsi sebagai perangkat yang terhubung langsung dengan internet dan server guna mengirimkan data dari setiap aktifitas yang terjadi pada vending machine melalui Arduino Uno.

\section{SOFTWARE}

Arduino Uno dijadikan sebagai kontroler utama pada Mesin Penjual Roti Otomatis Berbasis nternet of Things ini, dan Arduino IDE sebagai aplikasi yang digunakan untuk mengunggah program.

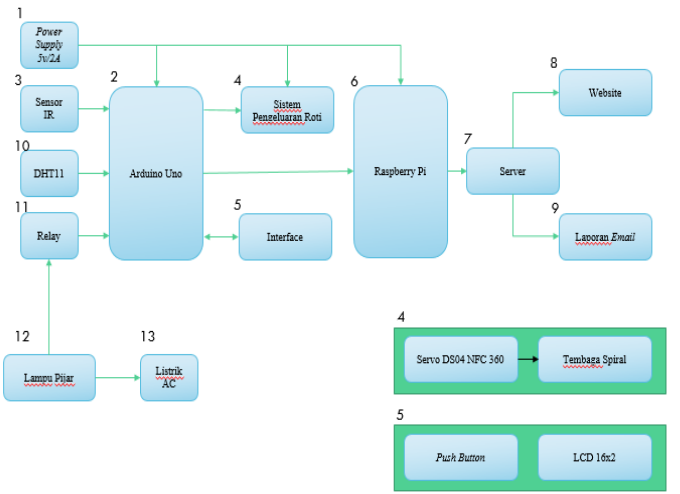

Gambar 4. Diagram blok sistem pada mesin penjual roti otomatis

Dalam digram blok diatas, dapat dibagi lagi menjad beberapa fokusan, sistem pengeluaran roti, sistem pembacaan data pada Arduino, server, dan sistem pengaturan suhu.

\section{A. Sistem Pengeluaran Roti}

Untuk sistem pengeluaran roti pada mesin penjual roti otomatis ini memanfaatkan servo DS04-NFC yang telah ditambahkan dengan kawat spiral, push button berguna untuk memberikan logika kepada Arduino Uno untuk memerintahkan salah satu servo untuk bergerak. Setelah itu Arduino Uno akan mengirimkan data kepada Raspberry Pi bahwa stok roti yang dipilih telah berkurang, keadaan ini akan terus terjadi berulang-ulang terkecuali pada keadaan dimana saat stok pada roti yang dipilih telah habis, apabila stok roti yang dipilih habis maka akan tertera tulisan pada LCD untuk memilih kembali roti, dan sistem diulang pada pemilihan barang.

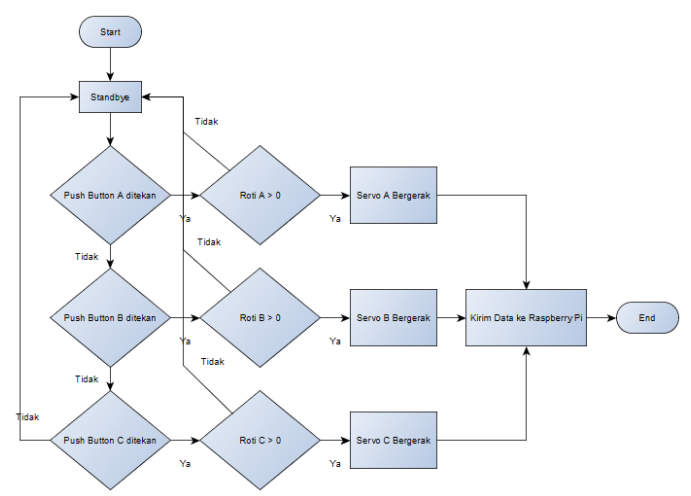

Gambar 5. Flowchart sistem pengeluaran roti

\section{B. Pembacaan Data pada Raspberry Pi}

Raspberry Pi membaca data dari Arduino dari Arduino atas segala aktifitas yang terjadi pada mesin penjual roti otomatis ini. Saat dilakukan pengisian ulang stok roti pada mesin, saat ada transaksi yang terjadi, dan saat stok roti sudah habis maka semua aktifitas tersebut akan direkam dan dikirimkan ke Raspberry Pi untuk di tindak lanjuti.

Berikut adalah proses yang terjadi pada Raspberry Pi, untuk penjelasannya adalah sebagai berikut:

1) F: Raspberry Pi mendapatkan data berupa pemberitahuan bahwa mesin penjual roti otomatis baru saja di isi ulang.

2) A--: Roti A telah terjual 1 buah.

3) B--: Roti B telah terjual 1 buah.

4) C--: Roti $\mathrm{C}$ telah terjual 1 buah. 


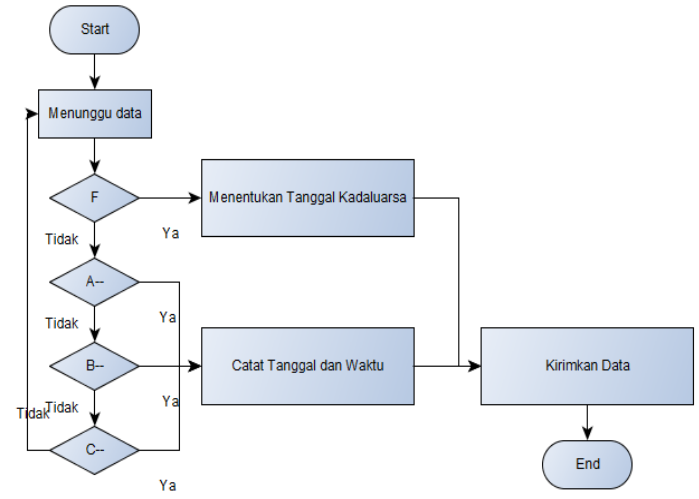

Gambar 6. Flowchart sistem pembacaan data pada Raspberry Pi.

\section{Server dan Website}

Raspberry Pi mengirimkan data kepada server untuk disimpan terlebih dahulu sebelum di upload pada website. Penulis menyewa jasa dari www.hostinger.co.id untuk dijadikan server bagi mesin penjual roti otomatis ini.

Tampilan website merupakan sebuah interface yang sangat memudahkan bagi penjual untuk memonitoring keadaan dari mesin penjual roti otomatis ini, bentuk dari website ini adalah berupa laman yang hanya dapat dimasuki oleh orang-orang yang memiliki akun, dalam hal ini yakni sang penjual. Desain dari website mesin penjual roti otomatis ini terbagi menjadi beberpa bagian, yang pertama adalah Halaman Login guna memastikan hanya para penjual yang mampu memonitoring mesin penjual roti mereka. Bagian kedua adalah Halaman Utama, menampilkan jumlah mesin penjual roti otomatis yang telah tersedia. Bagian ketiga yakni Stok Barang, menampilkan berapa macam jenis roti yang dijual, stok roti yang tersisa, dan waktu kadaluarsa bagi roti yang dijual, ini memudahkan bagi penjual untuk menentukan kapan harus mengisi ulang, ataupun mengganti stok roti yang di jual tanpa harus mengecek langsung ke masing-masing mesin penjual roti yang ditempatkan. Bagian keempat adalah Laporan Penjualan, berisikan grafik penjualan, dan detail penjualan per harinya pada mesin jual roti otomatis ini, sehingga para penjual dapat lebih mudah dalam mengetahui berapa jumlah dan kapan waktu bagi setiap pembelian roti. Bagian terakhir yakni untuk menambahkan akun ataupun admin untuk tiap mesin penjual roti otomatis.
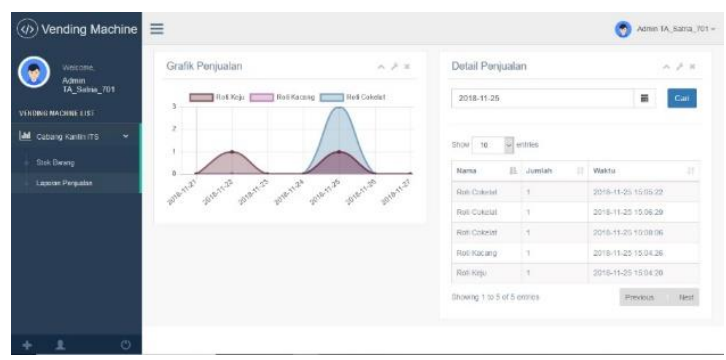

Gambar 7. Laporan penjualan pada website, menampilkan grafik serta data pada setiap transaksi yang terjadi [4].

\section{Pengaturan Suhu}

Sensor DHT11 pada alat ini difungsikan sebagai sensor suhu didalam vending machine ini, dan lampu pijar digunakan sebagai sumber panas. Penulis memberikan dua pilihan suhu pada alat ini yaitu mode warm, yang memiliki suhu $42^{\circ}$ celcius dan mode hot yang memiliki suhu $47^{\circ}$. Sistem yang digunakan ialah berupa on/off pada lampu pijar yang dihhubungkan dengan relay. Masing-masing mode memiliki suhu sesuai yang diatur dengan harapan hanya memiliki error $-+1^{\circ}$.

\section{HASIL}

Hasil dari pengujian-pengujian yang dilakukan atas sistem yang dijabarkan dapat merepresentasikan keberhasilan dari penelitian ini. Uji coba yang lakukan yang pertama yakni mengenai sistem pengeluaran roti. Pada sistem pengeluaran roti dilakukan percobaan dengan menggunakan servo DS04 NFC dan kawat spiral 7,5 mm. kawat cukup kuat dan baik pada saat eksekusi pengeluaran roti dengan kalibrasi dan pengujian servo sebagai berikut.

Tabel 1.

Hasil Kalibrasi Servo DS04-NFC

\begin{tabular}{ccccc}
\hline \hline No & Servo & \multicolumn{3}{c}{ Waktu yang dibutuhan $(\mathrm{ms})$} \\
\cline { 3 - 5 } & & Kosong & Sebagian & Penuh \\
\hline 1 & Servo 1 & 2050 & 2200 & 2200 \\
2 & Servo 2 & 2200 & 2350 & 2350 \\
3 & Servo 3 & 1800 & 2000 & 2000 \\
\hline \hline
\end{tabular}

Selanjutnya yaitu uji coba penerimaan data pada Raspberry Pi dan proses unggah pada server dan website, dengan tujuan untuk mengetahui apakah data telah benar-benar terkirim. Berikut gambar monitoring pada Raspberry Pi.

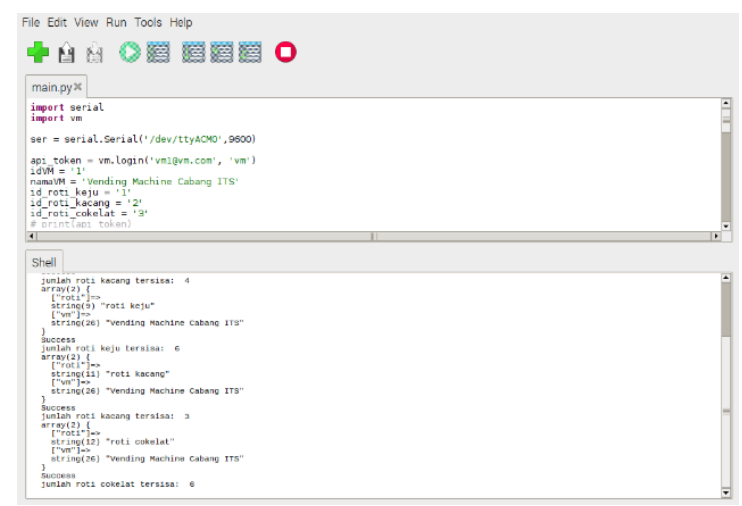

Gambar 8. Uji coba pengiriman data pada Raspberry Pi dan server.

Selanjutnya yakni pengujian kontrol suhu pada vending machine, alat ini memiliki 2 skala suhu, yakni $42^{\circ} \mathrm{C}$ dan $47^{\circ} \mathrm{C}$, lampu pijar digunakan sebagai sumber panas, terdapat dua jenis lampu pijar yang di uji coba, yakni 75 Watt dan 100 Watt, berikut hasil yang didapatkan.

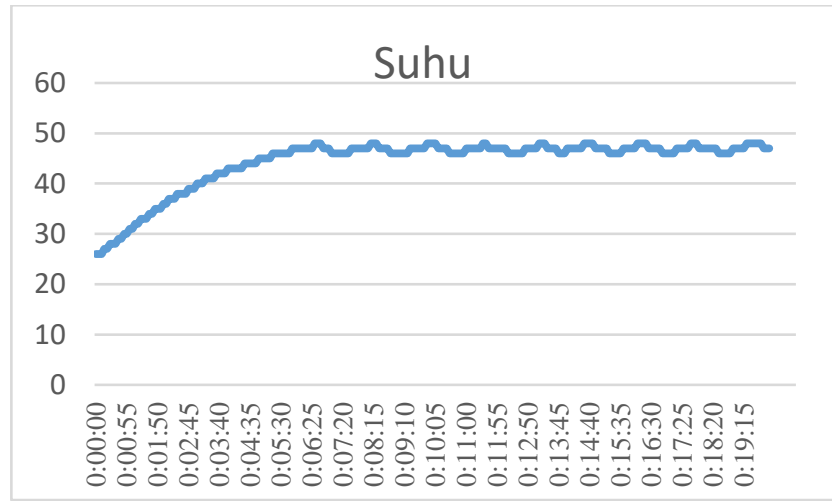

Gambar 9. Pengujian kontrol suhu $47^{\circ} \mathrm{C}$ dengan lampu pijar 100 Watt. 


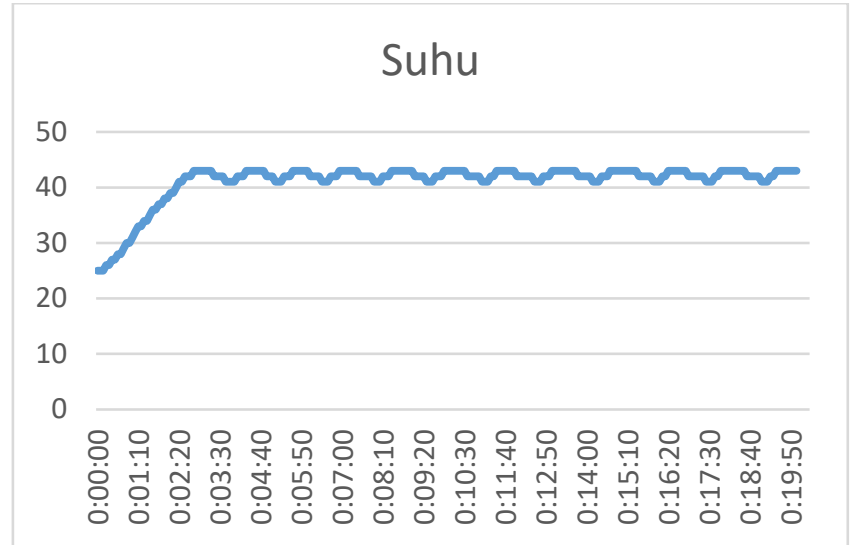

Gambar 10. Pengujian kontrol suhu $47^{\circ} \mathrm{C}$ dengan lampu pijar 75 Watt.

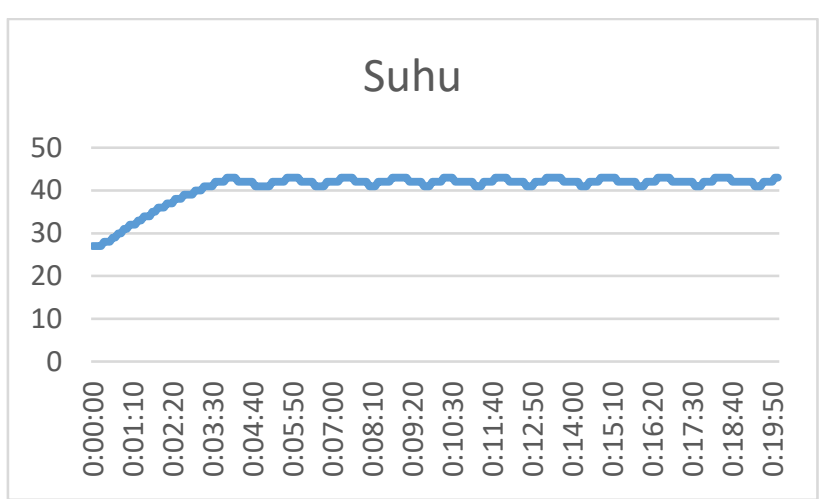

Gambar 11. Pengujian kontrol suhu $43^{\circ} \mathrm{C}$ dengan lampu pijar 100 Watt.

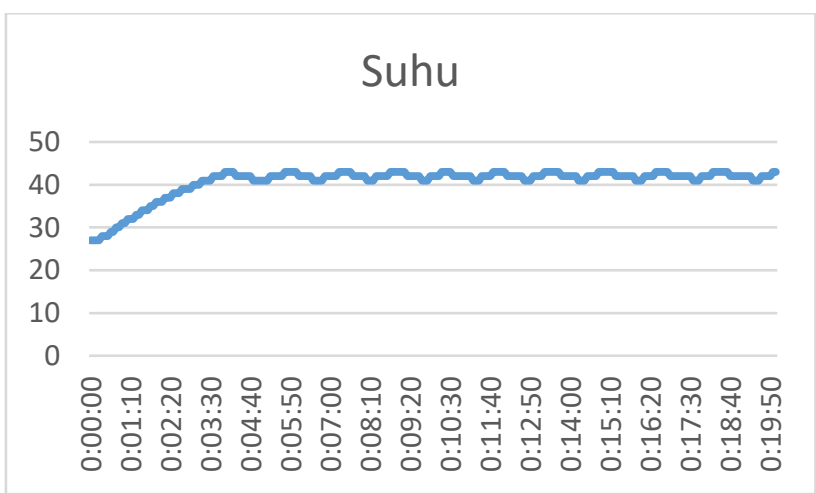

Gambar 12. Pengujian kontrol suhu $43^{\circ} \mathrm{C}$ dengan lampu pijar 75 Watt.

Penulis memutuskan untuk menggunakan lampu pijar 100 watt, karena memiliki percepatan penaikan suhu jauh lebih cepat dibandingkan dengan menggunakan lampu pijar 75 watt, baik peggunaan suhu 100 watt ataupun 75 watt, suhu yang didapatkan memiliki error suhu $\pm 1^{\circ}$, dimana saat suhu stabil dari yang diinginkan adalah $42^{\circ} \mathrm{C}$, maka suhu yang didapatkan adalah $41^{\circ} \mathrm{C}-43^{\circ} \mathrm{C}$.

\section{KESIMPULAN}

Berdasarkan percobaan yang telah dilakukan pada pelaksanaan penelitian ini didapat beberapa kesimpulan sebagai berikut:

1) Mesin Penjual Roti Otomatis Berbasis Internet of Thing dapat bekerja dengan baik dengan dimensi alat $(30$ x $60 \mathrm{x}$ 40) $\mathrm{cm}$.

2) Mesin Penjual Roti Otomatis Berbasis Internet of Thing ini memudahkan bagi para penjual yang memiliki keterbatasan ruang namun ingin menambahkan omset pendapat dari penjualan.

3) Sistem monitoring dengan website akan membantu bagi para penjual yang tidak dapat mengawasi secara langsung vending machine yang dimiliki.

4) Pemberitahuan melalui email akan membantu para penjual untuk mendapatkan pemberitahuan secara langsung atas aktifitas yang terjadi pada Mesin Penjual Roti Otomatis Berbasis Internet of Thing bagi penjual yang tidak sempat membuka website.

5) Proses pengiriman data mulai dari Arduino menuju Raspberry sampai server serta penampilan pada website dan pengiriman email tidak mengalami masalah selama jaringan internet dan server tidak mengalami gangguan.

6) Terjadi beberapa kali kegagalan pada pengeluaran roti apabila set awal ujung kawat spiral tidak sesuai atau dikarenakan roti tersangkut pada kawat.

7) Pengaturan suhu pada vending machine di set pada 2 keadaan, yakni $42^{\circ} \mathrm{C}$ dan $47^{\circ} \mathrm{C}$.

\section{DAFTAR PUSTAKA}

[1] M. N. Ridwan, "Otomasi Mesin Penjualan Minuman Berbasis Mikrokontroler," Universitas Gadjah Mada, 2016.

[2] "IR Infrared Obstacle Sensor Module," Elementz Engineers Guild Private Limited. [Online]. Available: https://www.elementzonline.com/ir-infrared-obstacle-avoidancesensor-module. [Accessed: 01-Dec-2018].

[3] C. N. A, "Data logger tingkat keasaman dan suhu berbasis arduino uno," Universitas Gadjah Mada, 2018.

[4] "Vending Machine | Laporan Penjualan." [Online]. Available: http://ta701.tech/Transaksi/index/1. [Accessed: 16-Dec-2018]. 